\title{
Hypophosphatemic Osteomalacia Associated with Tenofovir Use in HIV- Infected Patients: A Case Series and Review of the Literature
}

\author{
Angelique Tjen-A-Looi ${ }^{* *}$, Shabnam N Naseer ${ }^{1}$, Angus B Worthing ${ }^{2}$, Joseph G Timpone ${ }^{3 *}$ and Princy N Kumar ${ }^{4}$ \\ ${ }^{1}$ Clinical Infectious Diseases Fellow, Division of Infectious Diseases, Georgetown University Hospital, Washington DC, USA \\ ${ }^{2}$ Arthritis and Rheumatism Associates, PC, Washington, DC/Chevy Chase, MD, Georgetown University Hospital, Washington DC, USA \\ ${ }^{3}$ Associate Professor, Division of Infectious Diseases, Associate Program Director, Internal Medicine Residency Program, Georgetown University Hospital, Washington \\ DC, USA \\ ${ }^{4}$ Chief and Fellowship Director, Division of Infectious Diseases, Professor of Medicine and Microbiology, Department of Medicine, Vice Chair for Education, Associate Dean \\ for Students, School of Medicine, Georgetown University Hospital, Washington DC, USA
}

\begin{abstract}
We present three cases of HIV-infected patients who developed Fanconi syndrome, hypophosphatemic osteomalacia and bone fractures while on tenofovir, a nucleotide reverse transcriptase inhibitor, commonly used as part of HIV treatment. All patients presented with bone pain, electrolyte and radiographic abnormalities which improved with discontinuation of tenofovir. Although, there have been several studies demonstrating causality between tenofovir and Fanconi syndrome, there are only six previously reported cases of patients developing osteomalacia and fractures since the introduction of tenofovir in 2001. In addition to asymptomatic osteopenia, hypophosphatemic osteomalacia is an important, reversible adverse effect of tenofovir.
\end{abstract}

Keywords: HIV; Tenofovir; Osteomalacia; Hypophosphatemia; Fanconi syndrome

\section{Introduction}

Tenofovir (TDF) is a widely prescribed antiretroviral that combines potency, convenient dosing, and a favorable safety and tolerability profile. It is primarily eliminated by glomerular filtration and active tubular secretion. Despite cohort studies and clinical trials showing that the incidence of TDF-related renal dysfunction is very low, several case reports and animal studies have demonstrated evidence of renal toxicity including Fanconi syndrome, acute renal failure, interstitial nephritis and diabetes insipidus $[1,2]$.

The proposed mechanisms of TDF toxicity include mitochondrial injury and accumulation in the proximal tubule epithelial cells $[1,3]$. Fanconi syndrome, a rare disorder of the proximal renal tubule, consists of polyuria, dehydration, hypokalemia, hypophosphatemia, metabolic acidosis, and rickets in children and osteomalacia in adults. The mechanism includes impaired reabsorption of amino acids, glucose, uric acid, bicarbonate, and phosphate followed by spillage of these substances into the urine [4]. Energy derived to perform this reabsorption is dependent on the mitochondria of the tubule, and thus, any mitochondrial injury can cause significant wasting of these substances in the urine [3]. Over time, loss of phosphate together with incomplete synthesis of 1,25 dihydroxy vitamin D can cause phosphate depletion and inability to mineralize bone adequately [4].

Osteomalacia associated with Fanconi syndrome has been well established, and is usually seen in the setting of hypophosphatemia, low to normal 1, 25-dihydroxyvitamin $\mathrm{D}$, renal insufficiency, and chronic acidosis due to bicarbonate wasting [4]. It refers to a deficient mineralization of the osteoid matrix in modeling and remodeling sites.

However, limited data has been published about the role of TDF in bone disease. It is unclear whether or not TDF causes direct bone insult or if it is secondary to Fanconi syndrome and renal failure or both. Animal toxicology studies have shown that high-dose TDF produces an osteomalacia-like condition in the setting of normal renal function with subsequent fractures and bone deformities [3,5]. Clinical trials have shown increased bone turnover and decreased bone mineral density on TDF, however long-term bone health and fracture risk is unknown $[2,3]$.

Although, TDF is eliminated by active tubular secretion and glomerular filtration with predominant accumulation in proximal renal tubular cells, TDF-associated Fanconi syndrome with subsequent hypophosphatemic osteomalacia has been reported only a few times relative to the large number of patients taking TDF without adverse effects. In addition to under recognition of the symptoms of TDFassociated osteomalacia, one theory is that these patients may have an underlying mitochondrial DNA mutation or polymorphisms rendering them more susceptible to drug-induced mitochondrial injury [4].

In this case series, we present three HIV-infected patients on TDF that developed profound bone pain, myalgias, Fanconi syndrome, spontaneous fractures, and hypophosphatemic osteomalacia. We also review the limited published data on TDF and hypophosphatemic osteomalacia.

\section{Case 1}

A 46 year-old post-menopausal Caucasian female was diagnosed with AIDS and Hepatitis C in 1994. She completed treatment for

*Corresponding author: Angelique Tjen-A-Looi, Clinical Infectious Diseases Fellow, Division of Infectious Diseases, Georgetown University Hospital, Washington DC, USA, Tel: 916-973-5230; E-mail: Angelique.X.Tjen-A-Looi@kp.org

Joseph G Timpone, Associate Professor, Division of Infectious Diseases, Associate Program Director, Internal Medicine Residency Program, Georgetown University Hospital, Washington DC, USA, Tel: 202-444-0135; Fax 1-877-665-8072; E-mail: Timponej@gunet.georgetown.edu

Received October 13, 2012; Accepted October 26, 2012; Published October 29 , 2012

Citation: Tjen-A-Looi A, Naseer SN, Worthing AB, Timpone JG, Kumar PN (2012) Hypophosphatemic Osteomalacia Associated with Tenofovir Use in HIV Infected Patients: A Case Series and Review of the Literature. J AIDS Clin Res S4:008. doi:10.4172/2155-6113.S4-008

Copyright: (c) 2012 Tjen-A-Looi A, et al. This is an open-access article distributed under the terms of the Creative Commons Attribution License, which permits unrestricted use, distribution, and reproduction in any medium, provided the original author and source are credited. 
Citation: Tjen-A-Looi A, Naseer SN, Worthing AB, Timpone JG, Kumar PN (2012) Hypophosphatemic Osteomalacia Associated with Tenofovir Use in HIVInfected Patients: A Case Series and Review of the Literature. J AIDS Clin Res S4:008. doi:10.4172/2155-6113.S4-008

Page 2 of 4

\begin{tabular}{|c|c|c|c|c|c|c|c|c|c|}
\hline $\begin{array}{l}\text { Case } \\
\text { (Ref.) }\end{array}$ & $\begin{array}{l}\text { Age, } \\
\text { sex }\end{array}$ & Antiretrovirals* & $\begin{array}{l}\text { CD4, VL (cells/ } / \mathrm{LL}, \\
\text { (copies } / \mathrm{mL} \text { ) }\end{array}$ & $\begin{array}{l}\text { Dx of } \\
\text { AIDS }\end{array}$ & $\begin{array}{l}\text { Duration of } \\
\text { TDF mos. } \pm\end{array}$ & $\begin{array}{l}\text { Clinical } \\
\text { presentation }\end{array}$ & Site of fracture & Treatment & Outcome \\
\hline $1[3]$ & $45, \mathrm{~F}$ & DDI, LPV/RTV & $187,<400$ & Yes & 24 & $\begin{array}{l}\text { Shoulder, knee and } \\
\text { rib pain, FS after } \\
\text { osteomalacia }\end{array}$ & $\begin{array}{l}\text { Pathologic pelvic } \\
\text { and femoral neck }\end{array}$ & $\begin{array}{l}\text { Calcium, } \\
\text { Vitamin D }\end{array}$ & $\begin{array}{l}\text { Serum creatinine normalized, FS } \\
\text { resolved after } 3 \text { months }\end{array}$ \\
\hline $2[4]$ & $43, \mathrm{~F}$ & 3TC, LPV/RTV & $360, N / A$ & Yes & N/A & $\begin{array}{l}\text { Foot, hip, knee } \\
\text { pain, , FS }\end{array}$ & $\begin{array}{l}\text { Ankle and knee }{ }^{* *} \\
\text { Pathologic femoral } \\
\text { fracture }\end{array}$ & $\begin{array}{l}\text { Potassium, } \\
\text { Phosphate }\end{array}$ & Bone pain and FS improved \\
\hline $3[12]$ & $47, \mathrm{M}$ & $\begin{array}{l}\text { 3TC, DDI, LPVI } \\
\text { RTV }\end{array}$ & $200,<200$ & Yes & 16 & $\begin{array}{l}\text { Leg and heel pain, } \\
\text { FS }\end{array}$ & $\operatorname{Ribs}^{* *}$ & Phosphate & $\begin{array}{l}\text { Reduced bone pain, ALP resolved in } \\
8 \text { weeks; FS resolved over } 8 \text { months }\end{array}$ \\
\hline $4[12]$ & $56, \mathrm{~F}$ & ABC, LPV/RTV & 210,50 & Yes & 8 & $\begin{array}{l}\text { Knee and ankle } \\
\text { pain, proximal } \\
\text { myopathy, FS }\end{array}$ & N/A & $\begin{array}{l}\text { Phosphate, } \\
\text { Vitamin D }\end{array}$ & $\begin{array}{l}\text { FS resolved after } 2 \text { weeks, } \\
\text { myopathy; bone pains resolved over } \\
3 \text { months }\end{array}$ \\
\hline $5[13]$ & N/A & N/A & $\mathrm{N} / \mathrm{A},<50$ & N/A & 23 & "osteomalacia", FS & N/A & None & $\begin{array}{l}\text { FS resolved in 3-4 months. Per } \\
\text { authors, "Osteomalacia" and } \\
\text { elevated ALP not improved }\end{array}$ \\
\hline 6 [14] & $51, \mathrm{~F}$ & RTV, 3TC, ATZ & $290,<75$ & N/A & 16 & $\begin{array}{l}\text { Leg and foot pain, } \\
\text { FS }\end{array}$ & $\begin{array}{l}\text { Legs, feet, pelvis, } \\
\text { ribs** }\end{array}$ & $\begin{array}{l}\text { Phosphate, } \\
\text { Vitamin D }\end{array}$ & $\begin{array}{l}\text { Pain improved in } 2 \text { weeks and } \\
\text { resolved in } 8 \text { weeks, labs normalized } \\
\text { in } 12 \text { weeks }\end{array}$ \\
\hline 7 (case 1) & $46, F$ & $\begin{array}{l}\text { ABC/AZT/3TC, } \\
\text { LPV/RTV }\end{array}$ & $981,<50$ & Yes & 60 & $\begin{array}{l}\text { Foot, knee, chest } \\
\text { wall pain, FS }\end{array}$ & $\begin{array}{l}\text { Ribs, sacrum } \\
\text { knees, feet, } \\
\text { femur }{ }^{* *}\end{array}$ & Phosphate & $\begin{array}{l}\text { Pain improved in } 21 \text { days, and } \\
\text { resolved in } 2 \text { months, FS resolved }\end{array}$ \\
\hline 8 (case 2) & $55, \mathrm{~F}$ & $\begin{array}{l}\text { AZT/3TC,ATZ, } \\
\text { Raltegravir LPV/ } \\
\text { RTV }\end{array}$ & $341,<400$ & Yes & 60 & $\begin{array}{l}\text { Ankle, shoulder, } \\
\text { pain, L spine } \\
\text { compression } \\
\text { fracture, FS }\end{array}$ & $\begin{array}{l}\text { Ribs, thoracic } \\
\text { spine, sacrum }{ }^{* *}\end{array}$ & Phosphate & $\begin{array}{l}\text { Slow response after } 1 \text { month. } \\
\text { Phosphorus and GFR improved, ALP } \\
\text { remained high }\end{array}$ \\
\hline $\begin{array}{l}9 \text { (case } \\
3 \text { ) }\end{array}$ & $60, \mathrm{M}$ & LPV/RTV & $366<50$ & Yes & 48 & Foot, knee pain, FS & $\begin{array}{l}\text { Knees, feet, } \\
\text { femur** }\end{array}$ & $\begin{array}{l}\text { Calcium, } \\
\text { Phosphate, } \\
\text { Calcitonin } \\
\text { nasal spray }\end{array}$ & $\begin{array}{l}\text { Pain resolved in } 1 \text { month., FS } \\
\text { resolved, ALP decreased }\end{array}$ \\
\hline
\end{tabular}

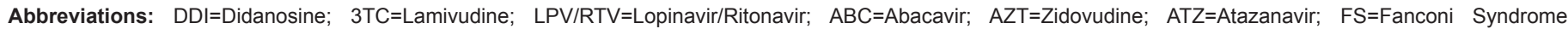
ALP=Alkaline Phosphatase; GFR=Glomerular Filtration Rate; $D x=$ Diagnosis

Notes: * in addition to TDF, ${ }^{ \pm}$months prior to symptoms ${ }^{1}$ TDF stopped in all cases. Case 2, all HAART stopped. ${ }^{* *}$ Stress fractures diagnosed by increased tracer activity on bone scan.

Table 1: Demographics and clinical outcomes in all 9 reported patients with TDF-associated osteomalacia

\begin{tabular}{|c|c|c|c|c|c|c|c|c|c|c|c|c|}
\hline Case (Ref) & $\begin{array}{l}\text { Phosphorus } \\
(2.2-5.1 \mathrm{mg} / \mathrm{dL})\end{array}$ & $\begin{array}{l}\text { Phos } \\
\text { (post) }\end{array}$ & $\begin{array}{l}\text { Bicarbonate } \\
(22-30 \mathrm{mEq} / \\
\mathrm{mL})\end{array}$ & $\begin{array}{l}\text { ALP } \\
(25-123 \text { U/L) }\end{array}$ & $\begin{array}{l}\text { ALP } \\
\text { (post) }\end{array}$ & $\begin{array}{l}\text { BMD }\left(\mathrm{gm} / \mathrm{cm}^{2}\right) \\
\text { L-spine, hip }\end{array}$ & $\begin{array}{l}\text { BMD (T-score) } \\
\text { L-spine, hip }\end{array}$ & $\begin{array}{l}\text { Creatinine baseline/peak } \\
\text { /post (0.4-1.1 mg/dL) }\end{array}$ & $\begin{array}{l}\text { GFR mL/min } \\
\text { (method) }\end{array}$ & Hypokalemia & $\begin{array}{l}\text { Glucosuria, } \\
\text { Proteinuria }\end{array}$ & $\begin{array}{l}\text { Vitamin D } \\
\text { deficiency }(1,25 \text { or } \\
25-\mathrm{OH})\end{array}$ \\
\hline $1[3]$ & 2.6 & NL & 14 & 516 & N/A & N/A & N/A & $1.3 / 2.0 / \mathrm{NL}$ & 24-31 (CG) & $\mathrm{N} / \mathrm{A}$ & Both & Yes $(25-\mathrm{OH})$ \\
\hline $2[4]$ & 1.8 & NL & 22.5 & 341 & N/A & $.899 / .631$ & $-2.3,-3.1$ & 1.1/1.3/NL & 33 (N/A) & Yes & Both & No \\
\hline $3[12]$ & 1.3 & NL & 20 & 358 & $\mathrm{NL}$ & N/A & -1.4 & $0.7 / 1.9 / \mathrm{NL}$ & N/A & No & Both & N/A \\
\hline $4[13]$ & 1.4 & NL & 20 & 310 & 170 & N/A & N/A & $0.8 / 3.9 / \mathrm{NL}$ & N/A & Yes & Both & No \\
\hline 5 [13] & 1.3 & $\mathrm{~N} / \mathrm{A}$ & N/A & 3194 & & N/A & N/A & $0.8 / 1.1$ & N/A & $\mathrm{N} / \mathrm{A}$ & N/A, Yes & N/A \\
\hline $6[14]$ & 1.5 & NL & N/A & N/A & N/A & N/A & N/A & N/A/1.5/NL & 39 (M) & N/A & Both & Yes $(25-\mathrm{OH})$ \\
\hline 7 (case 1) & 1.5 & 3.3 & 19 & 168 & 74 & N/A & $-1.9,-2.5$ & $0.8 / 1.4 / 1.0$ & 43 & Yes & Yes, N/A & No \\
\hline 8 (case 2) & 1.8 & 3.7 & 20 & 413 & 300 & N/A & $-2.7,-1.9$ & 0.8/1.3/1.11 & 44 & No & Both & Yes \\
\hline 9 (case 3$)$ & 1.4 & 3.0 & 21 & 221 & 63 & $1.04 / .68$ & $-1.7,-2.9$ & $1.1 / 1.6 / 1.5$ & $41(0)$ & No & Both & N/A \\
\hline
\end{tabular}

Abbreviations: ALP=Alkaline Phosphatase; BMD=Bone Mineral Density; GFR=Glomerular Filtration Rate; N/A=Not Available; NL=within Normal Limits, In GFR; M=MDRD; CG=Cockcroft-Gault; O=Other

Table 2: Laboratory Findings in patients with TDF-associated osteomalacia

hepatitis $\mathrm{C}$ with sustained virologic response. Her past medical history included Raynaud's disease. After failing multiple HIV regimens, she was started on a TDF-containing regimen in 2001. After 5 years on this regimen, she developed increasing pain in her feet, knees, and chest wall. She was unable to walk her dog, swim or hike, and her symptoms of Raynaud's became more pronounced. She lost five pounds due to appetite loss from pain, and she required narcotic analgesics.

A year prior to her symptoms, she had mild proteinuria and an elevated Alkaline Phosphatase (ALP). Two months prior to her symptoms, the serum phosphorus was found to be low, and phosphate supplementation was begun. A chest $\mathrm{x}$-ray showed subacute bilateral rib fractures. As the patient's GFR was significantly decreased, the dose of TDF was reduced to five times per week, and during the next month, her GFR increased to $50 \mathrm{~mL} / \mathrm{min}$. However, her symptoms worsened, and the TDF was discontinued in April 2007. Within 21 days, her pain dramatically decreased and she was able to ambulate without pain. The narcotics were tapered, and discontinued two months later. On subsequent follow-up, the bone pain had completely resolved, she was able to walk her dog, and her weight had stabilized. Also, her proteinuria, glucosuria, and serum phosphorus normalized, and the GFR increased to over $60 \mathrm{~mL} / \mathrm{min}$. Clinical characteristics and laboratory findings are reported in tables 1 and 2, respectively, for each patient case.

\section{Case 2}

A 55 year-old post-menopausal African American female was diagnosed with AIDS in 1987. After failing several HIV regimens, she was switched to a TDF-based regimen in November 2001. Two years later, she was given a non-TDF, protease inhibitor-based regimen for 

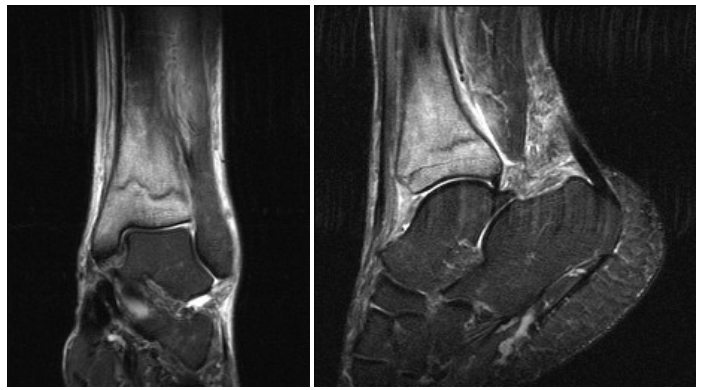

Figure 1: Case 2. MRI of Left Ankle; Distal tibial stress fracture; Broad linear band of sclerosis across the distal tibial metaphysis, representing stress injury.

virologic failure after which she developed severe hyperglycemia, likely secondary to the protease inhibitors. In December 2004, she resumed a TDF-containing regimen. Though intermittently, she had been on a TDF-based regimen for approximately five years. In the fall of 2006, she began to have severe myalgias and arthralgias. In November, she developed acute left ankle pain and swelling after walking for several hours, and complained of shoulder pain without antecedent trauma. An MRI of the ankle showed a stress fracture (Figure 1). Calcium and vitamin D supplementation was begun, but she had constant leg weakness, muscle spasms, back and rib pain requiring the use of a wheelchair.

There were low phosphorus levels since 2004, and she had been taking phosphate supplements for the past year. An ALP isoenzyme assay revealed a fraction of $85 \%$ from bone, $12 \%$ from liver and $3 \%$ from intestine. One month after TDF was discontinued, she had a slow and steady improvement in her symptoms, and her strength was regained. She reported some residual pain in her ribs; however imaging did not show any acute fracture. Her serum phosphorus and GFR improved, but the serum alkaline phosphatase remained elevated.

\section{Case 3}

A 60 year-old Caucasian male was diagnosed with AIDS in 2002. After virologic failure, he was prescribed a TDF-based regimen in August 2002. In October, 2006, he developed bilateral foot pains, which worsened with walking and did not improve with the use of fitted orthotics. After 5 months, he developed bilateral knee pains and myalgias in the quadriceps, for which he required a cane to walk. Ibuprofen helped, but renal insufficiency prompted a switch to narcotic analgesics and tramadol, which were less effective.

Biochemical testing showed progressive renal insufficiency had started one month prior to his symptoms. An MRI of the feet in April 2007 showed bony edema involving the cuneiforms, left anterior calcaneous, talus and the metatarsals. TDF was stopped in May 2007 and he was given phosphate and calcium supplementation, and calcitonin nasal spray for bone pain. After one month, his pain completely resolved. Serum phosphate normalized two weeks after stopping TDF, and ALP normalized five months later.

\section{Discussion}

Tenofovir is a novel nucleotide analogue with potent activity against both HIV and Hepatitis B, and with a long intracellular half-life that enables once daily dosing [2]. It is a component of two frequently used HIV medications, tenofovir and emtricitabine (Truvada, Gilead Sciences, Foster City, CA) and tenofovir, emtricitabine and efavirenz (Atripla, Bristol-Myers Squibb \& Gilead Sciences, Foster City, CA), both with once daily dosing that eases pill burden and improves patient adherence. Truvada is a preferred dual nucleoside reverse transcriptase inhibitor-combination (NRTI) with an AI recommendation (strong recommendation for the statement with one or more randomized trials with clinical outcomes and/or validated laboratory endpoints) according to the DHHS Guidelines [6]. In clinical trials, TDF, in combination with emtricitabine or lamivudine as part of an efavirenz based regimen in treatment-naïve patients, was found to be superior to zidovudine/ lamivudine in virologic efficacy at up to 144 weeks. Also, there was less anemia and lipoatrophy of the limbs and decreased development of resistance in the tenofovir-containing regimen according to Gilead studies 934 and 903, respectively [6].

Furthermore, increased bone turnover was reported without development of renal toxicity or Fanconi syndrome. In Gilead study 903, there was a significantly greater mean percentage decrease from baseline in Bone Mineral Density (BMD) at the lumbar spine (not at the hip) in patients receiving TDF, lamivudine, and efavirenz vs. those receiving stavudine, lamivudine, and efavirenz. In both groups, most of the reduction in BMD occurred in the first 24-48 weeks and was sustained throughout the study. Clinically relevant fractures occurred at the same rate in both groups. Biochemical markers of bone metabolism such as serum bone specific alkaline phosphatase, 1, 25 hydroxy vitamin $\mathrm{D}$, and serum osteocalcin were significantly higher in the TDF group, suggesting increased bone turnover $[7,8]$. However, potential fracture risk was unable to be ascertained given the relatively short treatment with TDF in this study (144 weeks).

Outside of clinical trials and cohort studies, however, TDF has now been shown to be associated with frank osteomalacia in 9 cases (Table 1). While HIV continues to evolve into a chronic disease, bone health has become increasingly important. As described earlier, the arthropathy can be quite disabling, and the need for earlier recognition of TDF-associated renal dysfunction, Fanconi syndrome, and bone disease, though rare as it may be, is essential. Symptoms of bone pain and myalgias can also lead to misdiagnoses, hospital admissions, and referrals to other providers such as rheumatologists, endocrinologists, orthopedists, podiatrists and chiropractors. In our first patient, for instance, a seronegative arthropathy was diagnosed initially, and methotrexate and hydroxychloroquine were prescribed until the diagnosis of TDF-associated osteomalacia was made.

Prior to the development of clinical features of osteomalacia (bone pain, myalgias, and stress fractures), all three patients had subtle abnormalities in their routine laboratory tests which included mild proteinuria, elevated ALP, and renal insufficiency (Tables 1 and 2). Hypophosphatemia, with mean phosphorus of $1.6 \mathrm{mg} / \mathrm{dL}$, was found in 8 out of 9 patients and is often present at the time of diagnosis. Hypophosphatemic osteomalacia was diagnosed clinically, and bone biopsies were not performed. The main sites of bone pain were in the lower extremities, particularly in the small joints of the feet. Pathologic and stress fractures occurred in 7 of the 9 cases, and the most common site was the femoral neck. Associated with bone pain, all but one of the patients had elevated ALP with a median of $350 \mathrm{IU} / \mathrm{L}$. The level of 1,25 dihydroxyvitamin $\mathrm{D}$ is usually low or normal in osteomalacia. In this series, data on $25-\mathrm{OH}$ vitamin D levels were available and were low or normal in 6 out of 9 cases [4].

All of the patients had further evidence of Fanconi syndrome, including low bicarbonate and increased urinary excretion of phosphorus, glucose, and protein. Hypokalemia was seen inconsistently. Hypophosphatemic osteomalacia occurred only in the context of Fanconi syndrome. While all 9 patients had Fanconi syndrome, one 
Citation: Tjen-A-Looi A, Naseer SN, Worthing AB, Timpone JG, Kumar PN (2012) Hypophosphatemic Osteomalacia Associated with Tenofovir Use in HIVInfected Patients: A Case Series and Review of the Literature. J AIDS Clin Res S4:008. doi:10.4172/2155-6113.S4-008

Page 4 of 4

developed a frank Fanconi syndrome after being diagnosed with hypophosphatemic osteomalacia. This raises the possibility of a direct effect of TDF on accelerated bone loss [3,9].

In the first two patients, decreased renal function was masked by a normal-appearing creatinine. Abnormal renal function may not be recognized in those with lower relative muscle mass (e.g., women, older patients, and those with lower lean body weights due to cachexia or liver disease) using serum creatinine alone. Therefore, equations which adjust for surrogates of muscle mass (age, weight, and sex), provide a more sensitive estimation of renal function [8].

Drug interactions may also play an important role in TDF exposure [10]. Ritonavir +/- lopinavir can increase the levels of TDF by 30$40 \%[2,4]$, thereby potentially worsening renal tubular disease. Also, atazanavir and TDF coadministration tends to increase the maximum concentration of TDF by $14 \%$ and its area under the curve by $22 \%$. Of note, in this case series, in addition to TDF, 6 of 9 patients were on lopinavir/ritonavir and 2 of 9 patients were on atazanavir at the time of presentation.

Patients on TDF should have routine phosphorus, potassium, ALP, and urinalysis for glucose and protein at regular intervals. If hypophosphatemia is noted, 24-hour urine measurements for phosphorus and other electrolytes may help diagnose Fanconi syndrome. Older patients and those with lower body mass index, for instance post-menopausal females, should be monitored by GFR rather than creatinine alone, and with dosage adjustments as needed. Any combination of TDF with atazanavir or lopinavir/ritonavir should be considered carefully for each patient. Since Truvada and Atripla are fixed-dose combinations that do not allow for dose adjustment, their use may not be acceptable for patients with decreasing renal function and worsening Fanconi syndrome. For prevention of bone disease, bone densitometry (DEXA) and vitamin D levels can be monitored closely. If there are any unexplained osteomalacia-like symptoms, especially bone pain and stress fractures, TDF should be discontinued immediately, with substitution of an appropriate agent. Mineral supplementation is unlikely to make a large impact in the majority of cases after osteomalacia has occurred $[3,4]$.

In addition, patients with low bone density are often treated with bisphosphonates without proper evaluation (i.e. excluding osteomalacia in the setting of renal insufficiency). Up to $30 \%$ of peri/ postmenopausal women and $50 \%$ of men with low bone density are categorized as primary osteoporosis when in fact they have secondary causes of bone loss [11]. HIV-infected patients on antiretroviral therapy, containing TDF, who have low bone density should not be treated with bisphosphonates empirically until hypophosphatemia or biochemical evidence of osteomalacia is ruled out, as the standard of care for osteomalacia is to treat the underlying cause. As HIV patients on TDF may be at increased risk for hypophosphatemia and or osteomalacia, they should undergo a complete evaluation prior to initiation of bisphosphonate therapy, which would unlikely be of benefit if TDF were contributing to the bone loss. Bisphosphonate therapy is currently recommended for primary osteoporosis, as opposed to osteomalacia, in the proper clinical setting.

Treatment with Highly Active Antiretroviral Therapy (HAART) has resulted in decreased mortality, and has changed HIV into a chronic manageable illness. As patients will require lifelong antiretroviral therapy, it is imperative for practitioners to recognize drug associated toxicities. Tenofovir associated bone disease can result in significant morbidity and its prompt recognition can result in reversal and improved quality of life for HIV-infected patients.

\section{References}

1. Sax PE, Gallant JE, Klotman PE (2007) Renal safety of tenofovir disoproxil fumarate. AIDS Read 17: 90-92, 99-104.

2. Viread (2006) prescribing information. Gilead Sciences, Foster City, California.

3. Brim NM, Cu-Uvin S, Hu SL, O'Bell JW (2007) Bone disease and pathologic fractures in a patient with tenofovir-induced Fanconi syndrome. AIDS Read 17: 322-328.

4. Earle KE, Seneviratne T, Shaker J, Shoback D (2004) Fanconi's syndrome in HIV+ adults: report of three cases and literature review. J Bone Miner Res 19 714-721.

5. Castillo AB, Tarantal AF, Watnik MR, Martin RB (2002) Tenofovir treatment at 30 $\mathrm{mg} / \mathrm{kg} /$ day can inhibit cortical bone mineralization in growing rhesus monkeys (Macaca mulatta). J Orthop Res 20: 1185-1189.

6. Department of Health and Human Services (2009) Panel on Antiretrovira Guidelines for Adults and Adolescents. Guidelines for the use of antiretroviral agents in HIV-1 infected adults and adolescents. 1-161.

7. Amorosa V, Tebas P (2006) Bone disease and HIV infection. Clin Infect Dis 42: $108-114$.

8. Gallant JE, Staszewski S, Pozniak AL, DeJesus E, Suleiman JM, et al. (2004) Efficacy and safety of tenofovir DF vs stavudine in combination therapy in antiretroviral-naive patients: a 3-year randomized trial. JAMA 292: 191-201.

9. Winston J, Shepp DH (2006) Estimating renal function in patients on tenofovir disoproxil fumarate: suggestions for safer use. HIV Med 7: 484-485.

10. Zimmermann AE, Pizzoferrato T, Bedford J, Morris A, Hoffman R, et al. (2006) Tenofovir-associated acute and chronic kidney disease: a case of multiple drug interactions. Clin Infect Dis 42: 283-290.

11. Fitzpatrick LA (2002) Secondary causes of osteoporosis. Mayo Clin Proc 77 453-468.

12. Parsonage MJ, Wilkins EG, Snowden N, Issa BG, Savage MW (2005) The development of hypophosphataemic osteomalacia with myopathy in two patients with HIV infection receiving tenofovir therapy. HIV Med 6: 341-346.

13. Kinai E, Hanabusa H (2005) Renal tubular toxicity associated with tenofovir assessed using urine-beta 2 microglobulin, percentage of tubular reabsorption of phosphate and alkaline phosphatase levels. AIDS 19: 2031-2033.

14. Perrot S, Aslangul E, Szwebel T, Caillat-Vigneron N, Le Jeunne C (2009) Bone pain due to fractures revealing osteomalacia related to tenofovir-induced proximal renal tubular dysfunction in a human immunodeficiency virus-infected patient. J Clin Rheumatol 15: 72-74.

This article was originally published in a special issue, Epidemiology and Prevention: HIV handled by Editor(s). Dr. Han-zhu Qian, Vanderbilt University School of Medicine, USA 